\title{
The LAMP instrument at the Linac Coherent Light Source free-electron laser
}

Timur Osipov, Christoph Bostedt, J.-C. Castagna, Ken R. Ferguson, Maximilian Bucher, Sebastian C. Montero, Michele L. Swiggers, Razib Obaid, Daniel Rolles, Artem Rudenko, John D. Bozek, and Nora Berrah

Citation: Review of Scientific Instruments 89, 035112 (2018); doi: 10.1063/1.5017727

View online: https://doi.org/10.1063/1.5017727

View Table of Contents: http://aip.scitation.org/toc/rsi/89/3

Published by the American Institute of Physics

\section{Articles you may be interested in}

Compact and tunable focusing device for plasma wakefield acceleration

Review of Scientific Instruments 89, 033302 (2018); 10.1063/1.5006134

A new device for high-temperature in situ GISAXS measurements

Review of Scientific Instruments 89, 035103 (2018); 10.1063/1.5005879

Relaxation calorimetry at very low temperatures for systems with internal relaxation

Review of Scientific Instruments 89, 033908 (2018); 10.1063/1.5018739

Experimental platform for investigations of high-intensity laser plasma interactions in the magnetic field of a pulsed power generator

Review of Scientific Instruments 89, 033504 (2018); 10.1063/1.5016973

A multifunctional force microscope for soft matter with in situ imaging

Review of Scientific Instruments 89, 043902 (2018); 10.1063/1.5018332

Invited Article: Refined analysis of synchrotron radiation for NIST's SURF III facility

Review of Scientific Instruments 89, 041301 (2018); 10.1063/1.5018412

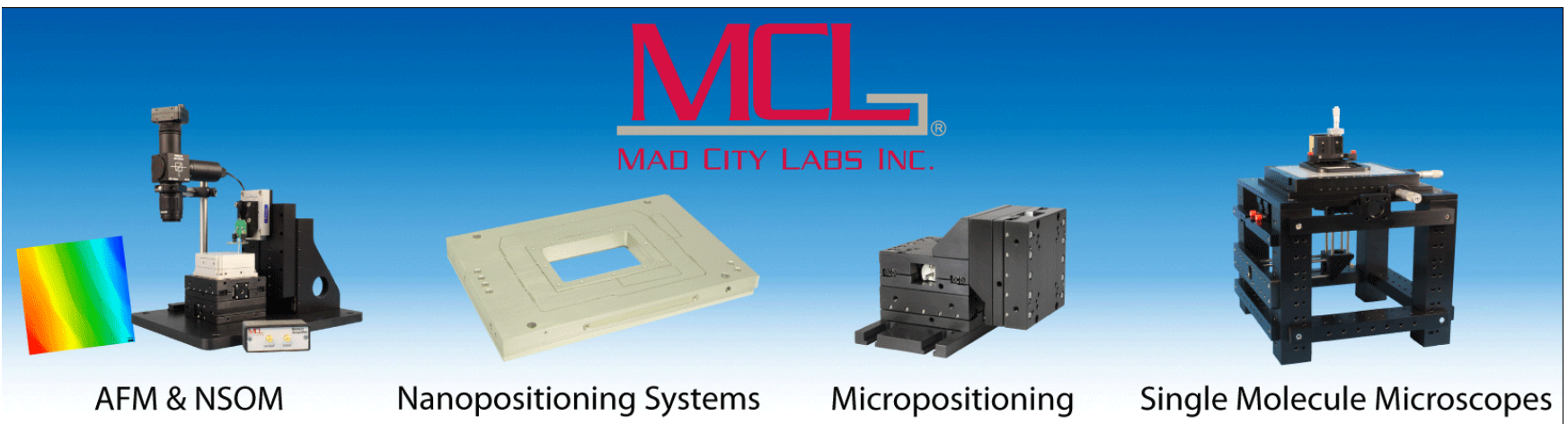




\title{
The LAMP instrument at the Linac Coherent Light Source free-electron laser
}

\author{
Timur Osipov, ${ }^{1,2,3, a)}$ Christoph Bostedt, ${ }^{2,4, b)}$ J.-C. Castagna, ${ }^{2}$ Ken R. Ferguson, ${ }^{2}$ \\ Maximilian Bucher, ${ }^{2}$ Sebastian C. Montero, ${ }^{2}$ Michele L. Swiggers, ${ }^{2}$ Razib Obaid, ${ }^{3}$ \\ Daniel Rolles, 5,6 Artem Rudenko, 5,6 John D. Bozek, 2,7 and Nora Berrah ${ }^{3, c)}$ \\ ${ }^{1}$ Physics Department, Western Michigan University, Kalamazoo, Michigan 49008, USA \\ ${ }^{2}$ LCLS, SLAC National Accelerator Laboratory, Menlo Park, California 94025, USA \\ ${ }^{3}$ Physics Department, University of Connecticut, Storrs, Connecticut 06269, USA \\ ${ }^{4}$ Chemical Sciences and Engineering Division, Argonne National Laboratory, 9700 South Cass Ave., \\ Lemont, Illinois 60439, USA \\ ${ }^{5}$ Center for Free-Electron Laser Science, DESY, Notkestrasse 85, 22607 Hamburg, Germany \\ ${ }^{6}$ J. R. Macdonald Laboratory, Kansas State University, Manhattan, Kansas 66506, USA \\ ${ }^{7}$ Synchrotron SOLEIL, L'Orme des Merisiers, Saint-Aubin, BP 48, F-91192 Gif-sur-Yvette Cedex, France
}

(Received 29 November 2017; accepted 4 March 2018; published online 23 March 2018)

\begin{abstract}
The Laser Applications in Materials Processing (LAMP) instrument is a new end-station for soft $\mathrm{X}$-ray imaging, high-field physics, and ultrafast X-ray science experiments that is available to users at the Linac Coherent Light Source (LCLS) free-electron laser. While the instrument resides in the Atomic, Molecular and Optical science hutch, its components can be used at any LCLS beamline. The end-station has a modular design that provides high flexibility in order to meet user-defined experimental requirements and specifications. The ultra-high-vacuum environment supports different sample delivery systems, including pulsed and continuous atomic, molecular, and cluster jets; liquid and aerosols jets; and effusive metal vapor beams. It also houses movable, large-format, high-speed pnCCD X-ray detectors for detecting scattered and fluorescent photons. Multiple charged-particle spectrometer options are compatible with the LAMP chamber, including a double-sided spectrometer for simultaneous and even coincident measurements of electrons, ions, and photons produced by the interaction of the high-intensity X-ray beam with the various samples. Here we describe the design and capabilities of the spectrometers along with some general aspects of the LAMP chamber and show some results from the initial instrument commissioning. Published by AIP Publishing. https://doi.org/10.1063/1.5017727
\end{abstract}

\section{INTRODUCTION}

High intensity $\left(10^{12}-10^{13}\right.$ photons per pulse) short-pulsed ( 10-200 fs) light sources such as X-ray free-electron lasers (FELs) ${ }^{1-7}$ have opened up new scientific and experimental possibilities, ${ }^{6-89}$ while also requiring the development of new, dedicated experimental instruments to meet the unique conditions and needs at these facilities. When an X-ray FEL beam is focused to a few-(or even sub-)micron spot, the reaction with the sample target can be extremely violent. Even a single molecule consisting of only a few atoms can eject tens of electrons, break up into several fragments, and produce multiple scattered and fluorescent photons. To get a grasp of such a reaction and to efficiently study all involved phenomena within the limited machine time available at FEL facilities, experimentalists require appropriate instruments and tools that can record many experimental observables in parallel and that can be configured to the specific needs of each individual experiment. The demand for such a versatile experimental setup that is capable of detecting multiple ions, electrons, and

\footnotetext{
a) tyosipov@slac.stanford.edu

b) cbostedt@anl.gov

c)nora.berrah@uconn.edu
}

photons and of recording comprehensive shot-by-shot information about their properties led to the construction of the Laser Applications in Materials Processing (LAMP) instrument that is available to all users at the Linac Coherent Light Source (LCLS), located at Stanford Linear Accelerator Center (SLAC) National Accelerator Laboratory. This instrument is presently housed in the Atomic, Molecular and Optical (AMO) science hutch of LCLS. Its construction was inspired by an earlier instrument called CFEL-ASG MultiPurpose (CAMP), ${ }^{90}$ which enabled many successful experiments during the first years of LCLS operation. ${ }^{60-87}$ LAMP brings forth several significant improvements and advancements over its predecessor. The new, highly flexible support stand, together with the modular design of the system in general, allows the use of the LAMP instrument as a whole, or of its individual components, at LCLS hutches and beamlines other than the AMO hutch. Positioned closer to the focusing optics in the AMO hutch than its predecessor CAMP, LAMP offers the possibility to considerably increase the FEL fluence on target, allowing the new instrument to be very effective with experiments requiring the highest photon densities, including single-particle imaging. Figure 1 illustrates the overall layout and geometry of the AMO beamline with all the main components of the LAMP chamber installed. With the distances from 


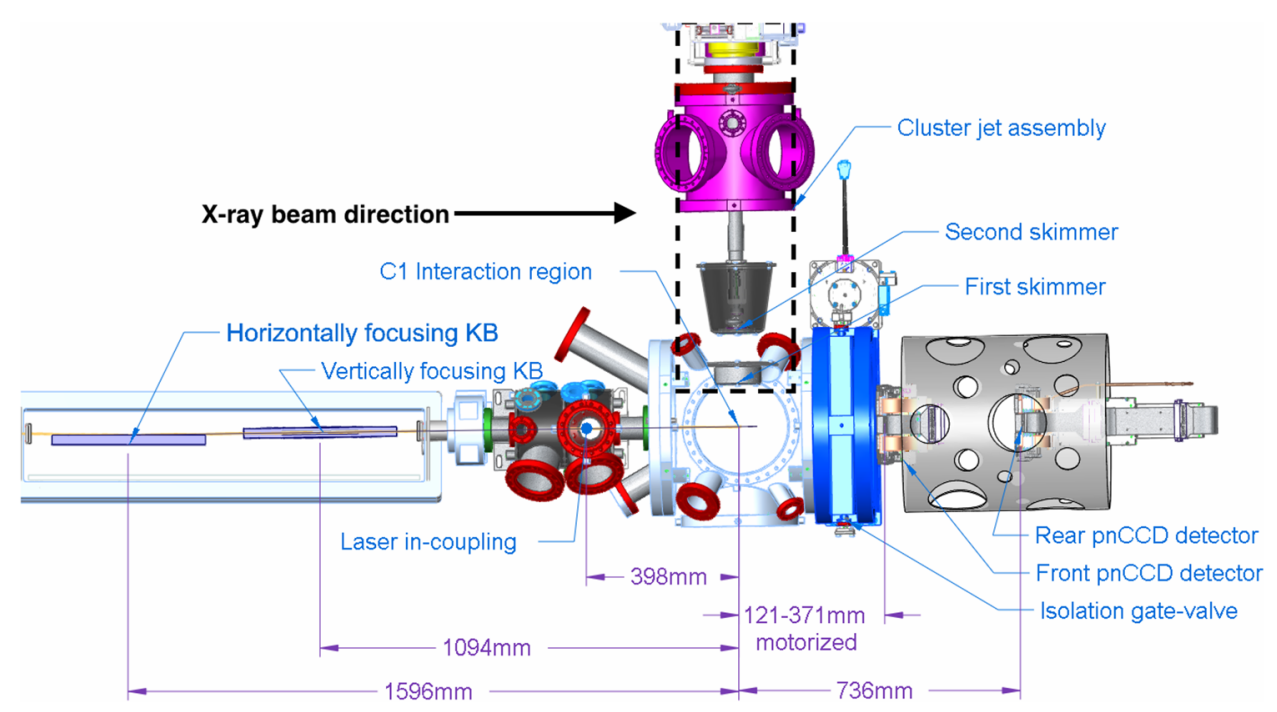

FIG. 1. Schematic top view of the LAMP instrument installed at the LCLS AMO beamline. The X-ray beam, entering from the left, is focused by two KB focusing mirrors, separated from the LAMP C1 interaction chamber by a differential pumping and laser in-coupling unit. Various spectrometers and sample delivery systems (a cluster jet assembly consisting of two skimmer chambers is shown here exemplary) can be attached to the four CF 250 ( 12 ") conflat flanges on $\mathrm{C} 1$, which is also equipped with several smaller flanges, to which other accessories such as beam viewing and diagnostics equipment can be connected. Scattered and fluorescent X-rays can be detected by two removable pnCCD detector planes, which can be isolated from $\mathrm{C} 1$ by a gate valve. The distances between the interaction region at the center of $\mathrm{C} 1$ and the $\mathrm{KB}$ focusing and laser in-coupling mirrors as well as the distances between the interaction region and the surface of the two pnCCD detectors are indicated.

the Kirkpatrick-Baez (KB) focusing mirrors to the interaction region as specified in Fig. 1, the LCLS beam can be focused to a spot of $2 \mu \mathrm{m}^{2}$ inside the LAMP chamber increasing the peak fluence by almost an order of magnitude over to the values achieved in CAMP for the same incident pulse energy. An improved pumping system together with a redesign of the movable, large-format, high-speed pnCCD detectors results in a better ultimate vacuum level of approximately $10^{-8} \mathrm{mbar}$ with pnCCDs installed. A renovated differential pumping stage combined with a new optical laser in-coupling unit facilitates multi-color, ${ }^{11,12,20,25,31,40-42,46,72,74,78,81,82,86}$ multibeam experiments. Numerous optical diagnostic tools can be mounted in the rear of the LAMP system or behind the laser out-coupling optics. A set of cameras, telescopes, interaction region paddles, and filters are available for precise beam profiling and adjustment. In addition, the LAMP end-station provides a suite of dedicated particle spectrometers that were designed for or made compatible with the LAMP interaction chamber. At the same time, scientists with established CAMP techniques, tools, and extensions will find maintained standards and full compatibility with the LAMP instrument geometries.

In the following sections, we will briefly describe the overall design of the LAMP instrument and discuss, in detail, the parameters and different modes of operation of the doublesided LAMP spectrometer that was designed and built specifically for the new instrument. The commissioning of the LAMP instrument took place in November 2013. Since then, numerous user experiments have utilized the instrument, already resulting in publications, ${ }^{45,91,92}$ while additional data are currently being analyzed. The complete system, supported and maintained by LCLS staff and AMO instrument scientists, is available to LCLS users through a peer-reviewed proposal process.

\section{LAMP VACUUM CHAMBER AND MOTION SYSTEM}

Figure 2(a) shows the main vacuum vessels of the LAMP instrument mounted on a motorized support stand that provides six degrees of freedom to freely position the instrument on the beamline. The LAMP instrument consists of an interaction chamber " $\mathrm{Cl}$ " (shown empty); a large gate valve with an inner diameter of $400 \mathrm{~mm}$, which can separate the interaction chamber from the pnCCD detectors; and the pnCCD detector enclosure system " $\mathrm{C} 2 .{ }^{.90}$ Further components that are not shown in the figure include the sample delivery systems, the differential pumping stage, laser in- and out-coupling units, and various vacuum diagnostics tools that can be connected to the $\mathrm{C} 1$ chamber or other subsections.

The movable stand that supports the entire instrument consists of two heavy duty stainless-steel (non-magnetic) frames [shown in blue in Fig. 2(a)] linked together by three support columns. Each column contains a vertical actuator that allows the plane of the top frame to be oriented arbitrarily with respect to the static bottom frame. A two-dimensional (2D) motion stage at the top of one of the columns [on the left in Fig. 2(a)] and a 1D stage at the top of another one [on the right in Fig. 2(a)] allow for independent translation and rotation of the top frame. Together with the motor control software for the motion stages, the stand is capable of rotations around any virtual axis in 3D space. At the same time, the open arrangement of the frames and the columns of the stand allows for unobstructed access to the vacuum chambers from all sides.

The reaction chamber $\mathrm{C} 1$ is the main vessel for housing different types of spectrometers, detectors, and diagnostic tools. The interaction region-the point where the X-ray beam typically hits the sample-is located at the 

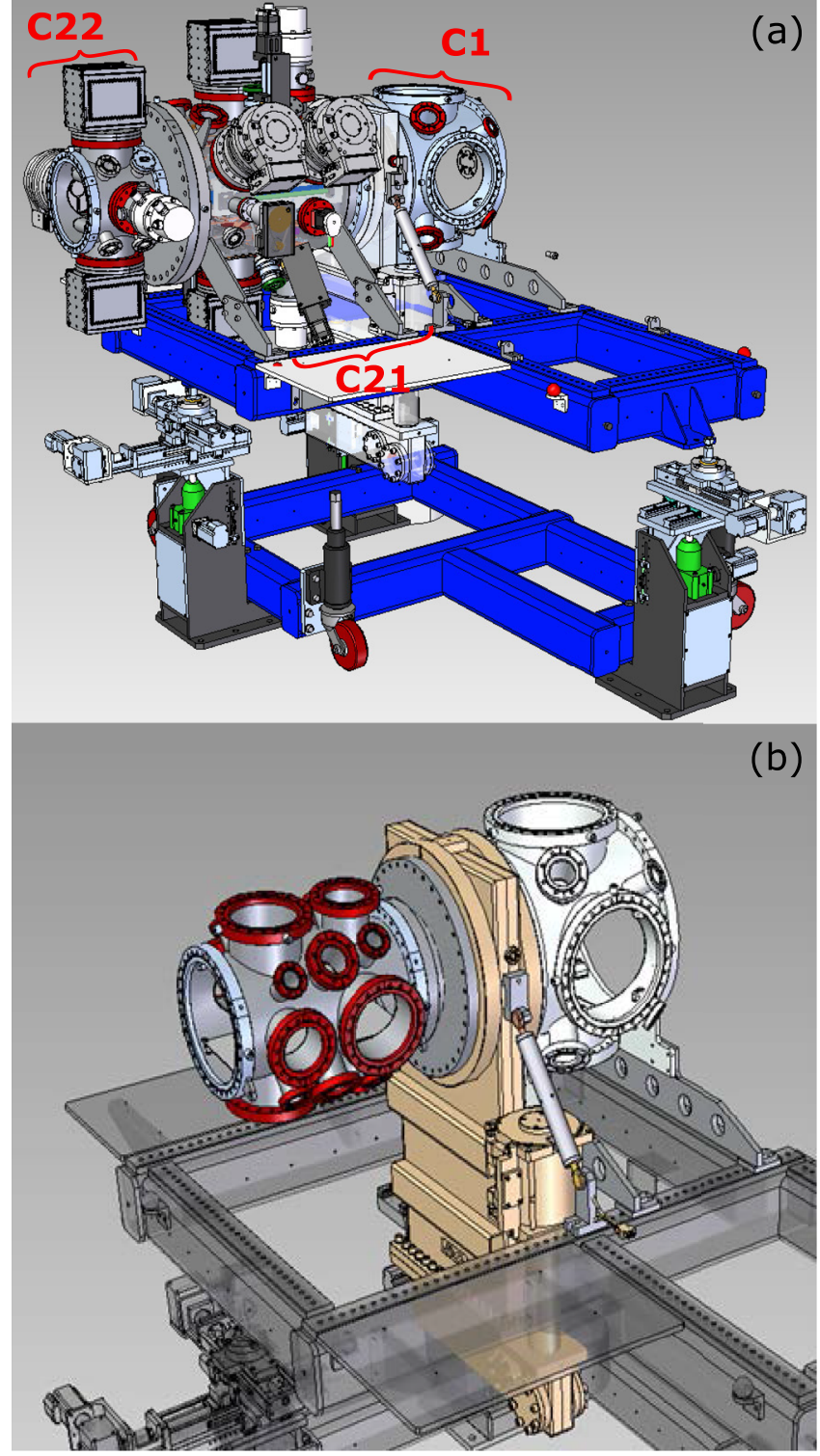

FIG. 2. Major components of the LAMP instrument mounted on the motorized support stand. (a) (from right to left) Interaction chamber- $\mathrm{C} 1 ; 400 \mathrm{~mm}$ ID gate valve; and pnCCD chamber- $\mathrm{C} 2(\mathrm{C} 21-$ for the front $\mathrm{pnCCD}, \mathrm{C} 22-$ for the rear pnCCD). (b) Alternate LAMP setup with the C2 system being replaced by a pumping cross (shown with red flanges) mounted downstream of the gate valve (shown in gold).

geometrical center of $\mathrm{C} 1$. The $\mathrm{C} 1$ chamber is essentially a six-way cross-the front and the back are custom-built $18^{\prime \prime} \mathrm{CF}$ flanges with $400 \mathrm{~mm}$ inner diameter, while the other four sides are symmetric $12^{\prime \prime} \mathrm{CF}$ ports. The distance from the face of the front flange to the face of the rear flange is $400 \mathrm{~mm}$, while the distances between the faces of the $12^{\prime \prime}$ flanges are $520 \mathrm{~mm}$. All eight diagonal corners of the cross also have smaller portsfour $2.75^{\prime \prime} \mathrm{CF}$ ports and four $4.5^{\prime \prime} \mathrm{CF}$ ports. All port axes intersect at the center of the chamber, with the distances from the face of the port to the center being $305 \mathrm{~mm}$ for all of the diagonal ports. Special holding brackets are welded inside the $\mathrm{C} 1$ chamber to allow bread-board or flat holding plates to be mounted inside each of the $12^{\prime \prime}$ and $18^{\prime \prime}$ flanges-at all 6 sides of the cross. The compact $\mathrm{C} 1$ chamber (together with the short differential pumping stage) allows the interaction region, the center of $\mathrm{C} 1$, to be placed at the shortest focusing distance of the X-ray beam available in the AMO hutch, which is approximately $110 \mathrm{~cm}$ from the center of the last KirkpatrickBaez mirror. This ensures that the smallest possible focus size and thus the highest possible X-ray intensity can be achieved.

The large gate valve between the $\mathrm{C} 1$ and $\mathrm{C} 2$ chambers facilitates venting one of the chambers while keeping the other under vacuum. This is particularly important if the $\mathrm{C} 1$ chamber needs to be vented, e.g., for a sample change, while the pnCCD detectors in $\mathrm{C} 2$ are at their sub $0{ }^{\circ} \mathrm{C}$ operating temperature, since it drastically shortens the venting procedure if the pnCCDs do not have to be warmed up to room temperature. Depending on the particular needs of the experiment, pumping of the $\mathrm{C} 1$ chamber can be done via turbomolecular pumps attached to one or several of the $12^{\prime \prime}$ ports and/or via additional turbo-pumps installed on the $\mathrm{C} 2$ chamber. In this arrangement, the ultimate pressure in $\mathrm{C} 1$, with the $\mathrm{pnC}$ $\mathrm{CDs}$ attached in $\mathrm{C} 2$, is typically in the low $10^{-8}$ mbar range. To improve the vacuum further, installation of a cryo-cooling head (opposite of the sample delivery system, for example) can be considered. On the other hand, if the pnCCD detectors are not needed for a given experiment, the whole $\mathrm{C} 2$ chamber can be replaced by a pumping cross, as shown in Fig. 2(b). The main body inner diameter of the cross is $\sim 250 \mathrm{~mm}$, with four 8 " CF ports for large-capacity turbomolecular pumps and with multiple auxiliary ports of $6^{\prime \prime}, 4.5^{\prime \prime}$, and $2.75^{\prime \prime}$ sizes available perpendicular to the FEL beam direction. Without the pnCCD detectors and all associated motion stages, mounting hardware, and wiring, the pressure in $\mathrm{C} 1$ can reach the $10^{-10}$ mbar range, even with the gas jet and the ion and/or electron spectrometers installed.

\section{CHARGED-PARTICLE SPECTROMETERS}

In keeping with the idea of LAMP being a flexible and modular system, the existing AMO hutch ion spectrometers [an integrating ion time-of-flight (TOF) spectrometer and an ion momentum imaging spectrometer ${ }^{93}$ ] as well as all diagnostics tools and instruments (interaction region microscope; different types of cameras, etc.) developed for the AMO highfield physics (HFP) chamber $^{93,94}$ are compatible with the LAMP C1 chamber. In addition, a dedicated double-sided electron-ion spectrometer was designed and constructed for the LAMP C1 chamber. This spectrometer allows for simultaneous and, under certain conditions, coincident measurements of all charged particles while also providing a large solid angle for detection of fluorescent or scattered photons, for example, on the pnCCD detectors. In the following, we will present detailed descriptions and specifications of the available spectrometers.

\section{A. Integrating ion time-of-flight spectrometer}

The integrating ion time-of-flight (TOF) spectrometer [see Fig. 3(a)] comprises two sections-an interaction/acceleration section and a drift tube. A $120 \mathrm{~mm}$ diameter MCP stack is positioned $10 \mathrm{~mm}$ behind the drift tube for charged particle detection. The acceleration section, which contains the 

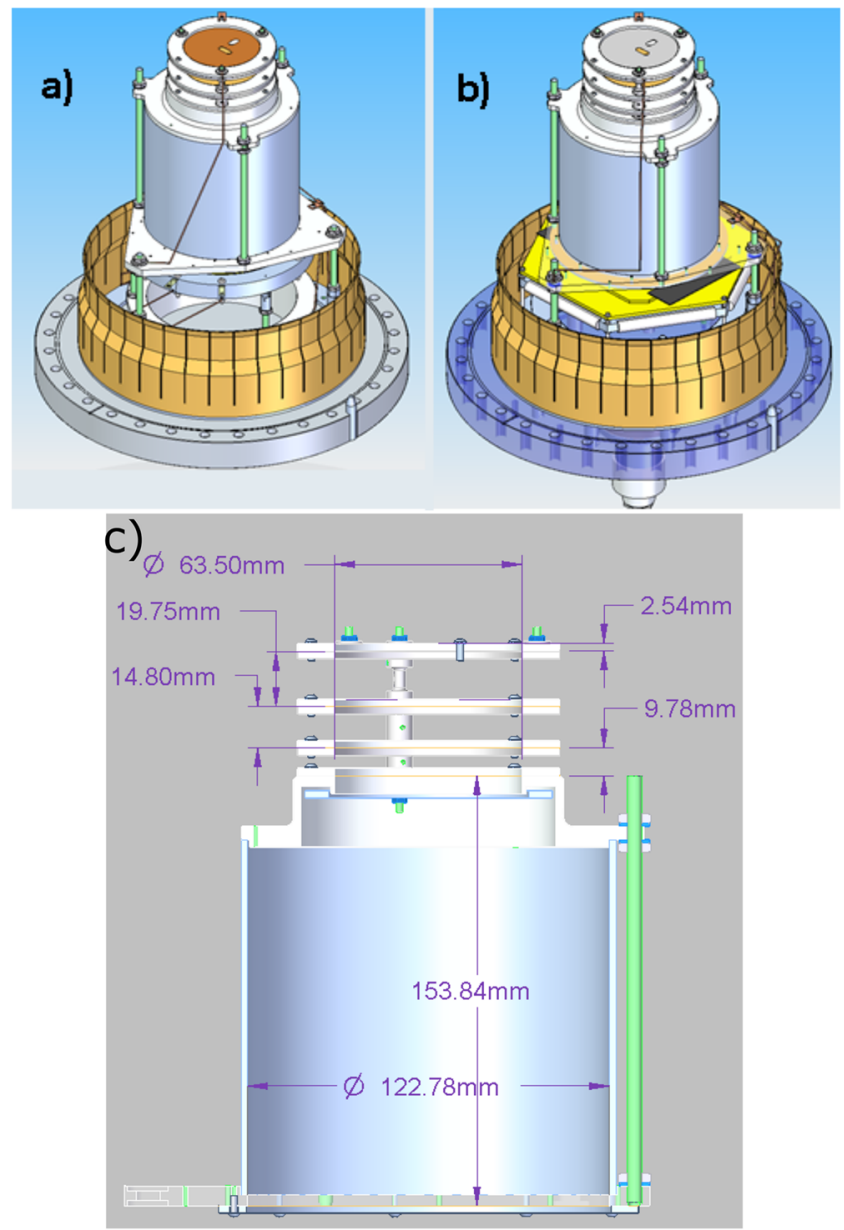

FIG. 3. Schematics of (a) the integrating ion time-of-flight (TOF) spectrometer and (b) the ion momentum imaging spectrometer on the appropriate $12^{\prime \prime} \mathrm{CF}$ mounting flanges. (c) Cross section of the ion momentum imaging spectrometer with the relevant dimensions.

interaction region, consists of a pusher plate and a flat ring as an extractor, separated by $20 \mathrm{~mm}$, with the interaction point exactly in the middle between the two. The next electrode, typically represented by a $\sim 75 \%$ transmittance gold mesh, is at the same potential as the drift tube and is $15 \mathrm{~mm}$ behind the extractor plate. The length of the drift region is $155 \mathrm{~mm}$. While it is possible to use the extractor ring to set up either a uniform flat field (by applying all the voltages proportional to the electrode distances) or an electrostatic lens (by applying a voltage that is not consistent with a flat field between the pusher and the drift tube mesh), the most commonly used configuration thus far was to replace the extractor ring by a thin plate with a $10 \mathrm{~mm} \times 1 \mathrm{~mm}$ slit oriented with its long side perpendicular to the beam polarization direction. This cuts the detected area to the FEL beam focus and the accepted solid angle along the FEL beam direction and thus suppresses the number of ions hitting the MCP detector, which is very useful in case of experiments with very high ion yield as, for example, in the case of a high-intensity FEL interacting with clusters. ${ }^{68,88,95}$ A typical ion time-of-flight spectrum obtained with this spectrometer for a target containing atomic Xe as well as Xe clusters at four different LCLS photon energies is shown in Fig. 4. The graph reflects the charge state distributions of the created Xe ions.

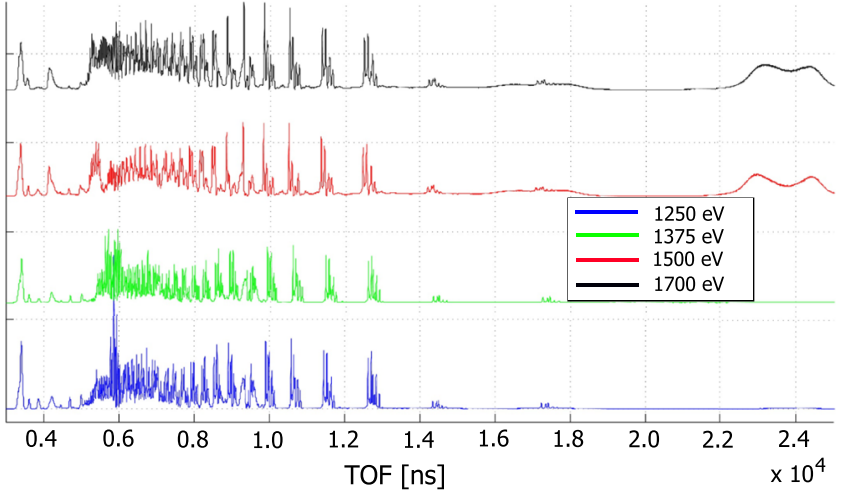

FIG. 4. Ion time-of-flight (TOF) spectrum of a target containing atomic Xe as well as Xe clusters ionized at four different photon energies, obtained with the integrating ion TOF spectrometer using a slit extractor electrode.

The spectrometer voltages applied during this data collection (typical for most experiments that utilized this spectrometer) were $0 \mathrm{~V}, 571 \mathrm{~V}$, and $1000 \mathrm{~V}$ on the pusher, extractor, and drift tube, respectively. Individual Xe isotopes can be clearly resolved for charge states up to approximately $\mathrm{Xe}^{10+}$ but begin to merge for higher charges.

\section{B. Ion momentum imaging spectrometer}

The second existing spectrometer that was made compatible with the LAMP setup is the ion momentum imaging spectrometer, depicted in Fig. 3(b). The main difference between this spectrometer and the integrating ion TOF spectrometer is the use of a Roentdek HEX-anode delay-line detector. By simultaneously measuring the TOF and the position of each ion hit, this detector allows for complete coincident 3D ion momentum reconstruction on an event-by-event basis. Apart from the detector, the spectrometer has only minor geometry differences from the integrating ion TOF spectrometer. One extra flat ring (lens) is added $15 \mathrm{~mm}$ behind the extractor electrode, and the drift tube is moved back a further $10 \mathrm{~mm}$. The front surface of the Z-stack MCP detector is typically $7 \mathrm{~mm}$ behind the rear mesh of the drift section. Figure 5 shows exemplary ion-ion coincidence data collected with the ion momentum imaging spectrometer equipped with the HEX delay-line detector. It shows the fragmentation of $\mathrm{CO}$ molecules by $400 \mathrm{eV}, 10 \mathrm{fs}, 100 \mu \mathrm{J}$ LCLS pulses. Figure 5(a) depicts the photoion-photoion coincidence (PIPICO) spectrum, while the non-coincident ion yield plotted as a function of the measured TOF and hit $(X)$ position on the delay-line detector is shown in Fig. 5(b), and the corresponding TOF spectrum integrated over all hit positions, in Fig. 5(c). The circular structures in Fig. 5(b) represent the two-dimensional projections of the momentum spheres for the different species of molecular ion fragments. Due to the extra lens, the spectrometer voltages can be applied to either create uniform flat fields throughout the whole volume in order to operate as a so-called reaction-microscope (ReMi) or COLTRIMS ${ }^{96,97}$ or to produce a velocity map imaging (VMI) configuration, ${ }^{98}$ where the ion trajectories are focused in such a way that only the ions' original velocity vector (and not their starting position) defines their final position on the 

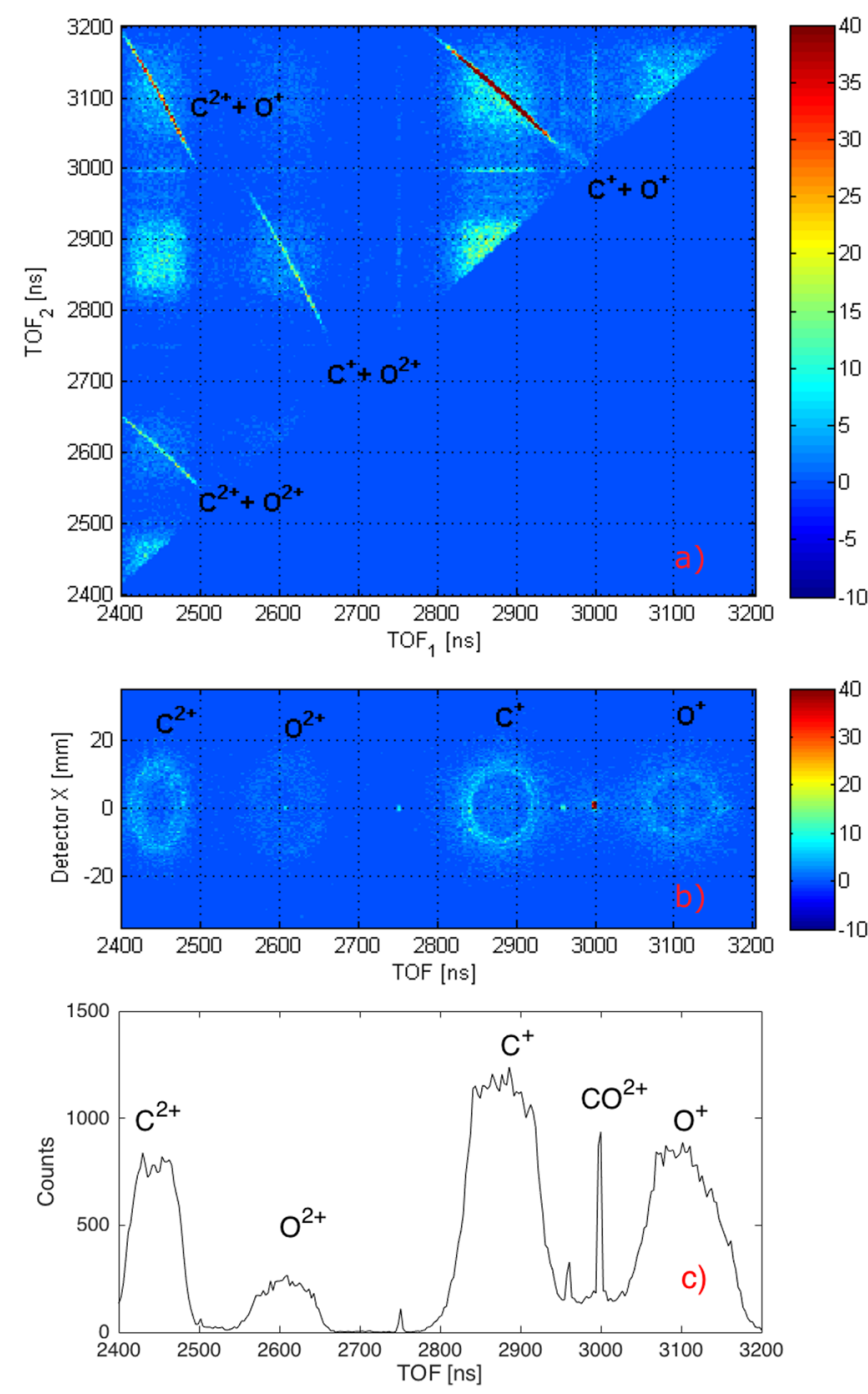

FIG. 5. (a) Photoion-photoion coincidence (PIPICO) spectrum of a molecular $\mathrm{CO}$ target collected with the ion momentum imaging spectrometer. Corresponding ion yield plotted as (b) a function of the measured TOF and hit (X) position on the delay-line detector and (c) integrated over all hit positions.

detector. Typical voltage settings for operation in the ReMi mode are given in Table I in the Appendix.

Both of the aforementioned spectrometers allow for some simple geometry modifications if necessary for the experiment, such as shortening the drift tube, changing distances between the lenses, or adding or replacing meshes. In the case of the ion momentum imaging spectrometer, such modifications were already performed based on user requirements.

\section{Double-sided electron-ion momentum imaging spectrometer}

Similar to the double-sided electron and ion spectrometers in the CAMP instrument, ${ }^{82,90}$ the main purpose of the double-sided LAMP electron-ion momentum imaging spectrometer (Fig. 6) is to allow for simultaneous or even coincident detection of electrons and ions over the full solid angle, while simultaneously providing an unobstructed line of sight from the interaction region to the pnCCD photon detectors. In the following, the key features of the design are pointed out.

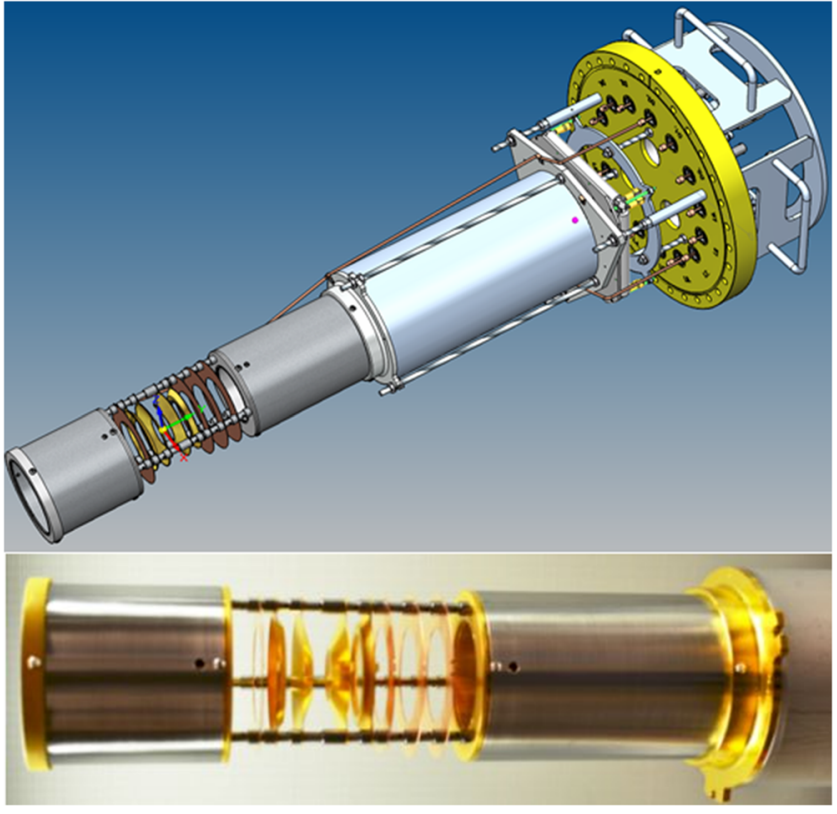

FIG. 6. Double-sided LAMP electron-ion momentum imaging spectrometer: 3D CAD rendering (top) and photograph of the spectrometer during its assembly (bottom). Both sides of the detector can be equipped with delay-line or $\mathrm{MCP} /$ phosphor screen detectors.

For further details, the complete engineering drawings of all the elements and the final assemblies as well as the complete set of SIMION simulation files for either VMI or ReMi configuration (see Fig. 7) can be made available to LCLS users upon request.

The double-sided LAMP electron-ion momentum imaging spectrometer, as well as the other spectrometers discussed

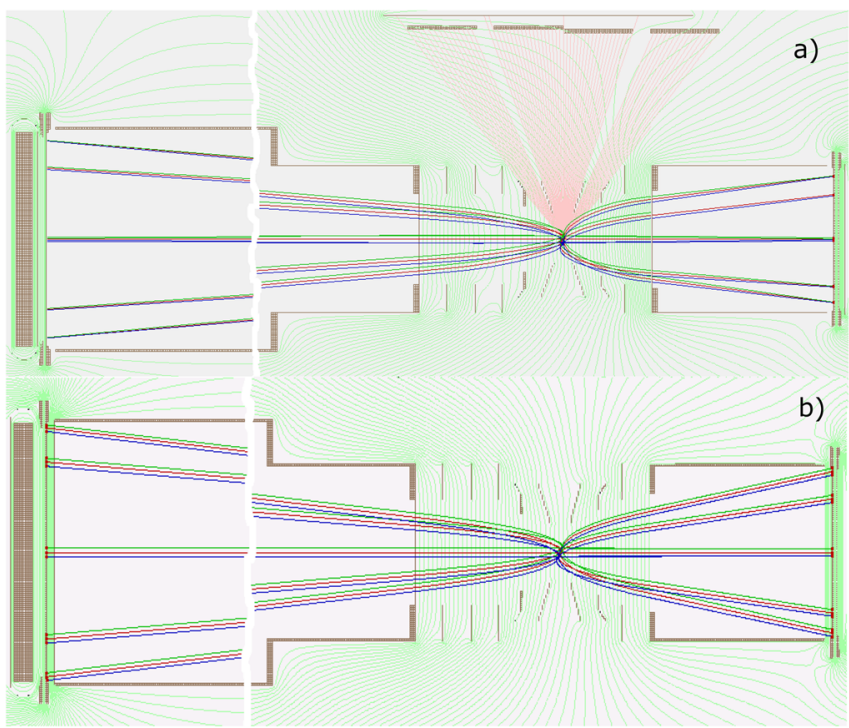

FIG. 7. SIMION simulation of the double-sided LAMP electron-ion momentum imaging spectrometer operated in the (a) VMI and (b) reaction microscope mode. Ion (toward the left), electron (toward the right), and photon (toward the top) trajectories are shown as colorful lines, equipotential surfaces in light green. For the sake of the compactness of this image, the middle part of the ion drift tube is not shown. 
earlier, is normally installed vertically inside the LAMP chamber. Much of its design was dictated by the geometry of the pnCCD X-ray imaging detectors. Specifically, the front pnCCD detector (i.e., the detector closest to the interaction region) is movable parallely and perpendicularly to the $\mathrm{X}$-ray beam direction. The closest placement of the detector to the interaction region, in the presence of the spectrometer, is $120 \mathrm{~mm}$. The dimensions of the active area for each of the front pnCCD halves are $38.3 \mathrm{~mm} \times 75 \mathrm{~mm}$. The maximum gap (y-axis) between the two detector halves is $96.6 \mathrm{~mm}$. As shown schematically by the pink rays in the SIMION image in Fig. 7 as well as in the interaction region diagrams in Fig. 8, the conical spectrometer electrodes fully accommodate for any position of the pnCCD detector halves. When the pnCCDs are in the fully closed position, the inner two conical electrodes provide for a completely unobstructed line of sight of the whole pnCCD surface from the reaction center. When the pnCCD halves are fully opened, the combination of two different conical rings on each side of the interaction region results in minimal shadowing of the detector surface. Similarly, for the pnCCD configuration, where, for example, one half is completely "in" (small angle photon diffraction) and another half is "out" (simultaneous large angle fluorescence), the spectrometer design offers minimal detector shadowing.

The conical electrode rings around the center of the spectrometer were machined out of oxygen-free aluminum and coated with gold to ensure a uniform surface work function and to avoid field fringe effects due to an aluminum oxide layer. All the flat rings are machined out of copper. Both conical and flat rings allow for installation of meshes as well as pinholes or slotted plates, if required. The electrode plates are held together by PEEK insulators, which are covered by stainless steel sleeves. Each metal sleeve is in contact with the appropriate adjoining spectrometer electrode and extends about half the distance to the next one. Neighboring sleeves are made to overlap without electrical contact to completely shield the PEEK elements and prevent surface charge effects. By splitting the voltage between the adjacent electrodes, the sleeves also serve to minimize field distortions due to the spacer. Another important aspect that was found to be very sensitive to the geometry of the electrode rings and in particular to their spacing is fringe field leakage into the interaction region due to the proximity of external surfaces such as the jet skimmer, beam

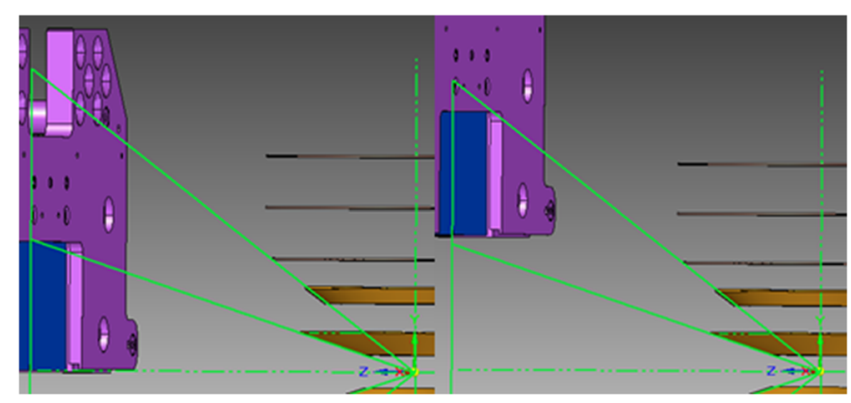

FIG. 8. Schematics of the Line Of Sight (LOS) of the pnCCD detector as seen from the interaction region past LAMP spectrometer rings: pnCCD half fully in (left) and fully out (right). apertures, and filters and even the active surfaces of the pnCCD detector. The present conical and flat rings' placement was found to be the optimal compromise that provides clear line of sight of the interaction point for a large solid angle, while still preventing significant field distortions due to external potentials.

SIMION simulations of the ion and electron trajectories in the double-sided LAMP spectrometer in Fig. 7 show that it is possible to achieve simultaneous focusing of the ion (longer side) and electron (shorter side) trajectories. Table II in the Appendix lists the voltages used to produce this double-sided velocity map imaging (VMI) field arrangement. In this case, ions with a kinetic energy up to $50 \mathrm{eV}$ per unit-charge and electrons with up to $150 \mathrm{eV}$ kinetic energy can be collected over the full $4 \pi$ solid angle. These settings were found to be the most common compromise between spectrometer resolution and energy acceptance for the atomic and molecular reactions studied so far. However, to provide the possibility to increase this range, we installed $10 \mathrm{kV}$ rated electrical feedthroughs on the LAMP spectrometer vacuum flanges, which should allow for nearly doubling the kinetic energies of the particles that can be detected within the full solid angle if appropriate $10-\mathrm{kV}$ power supplies are used. (The spectrometer plates and insulators are vacuum rated to hold few tens of $\mathrm{kV}$ voltages.) On the other hand, if the experiment calls for only one side of the spectrometer to be operational at a time, the energy of the electrons that can be detected with $4 \pi$ efficiency could be as high as $400 \mathrm{eV}$; alternatively, on the long side of the spectrometer, ions up to $200 \mathrm{eV} /$ unit-charge could be collected with $4 \pi$ solid angle detection. However, one has to take into account that increasing the field in the interaction region typically leads to the compression of any charged particle TOF spectrum and thus decreases the energy resolution. For example, the choice of the fields illustrated in Fig. 7(a) provides enough TOF spread to completely distinguish singly charged oxygen ions from singly charged nitrogen ions, while both are at energies of $0-50 \mathrm{eV}$.

Due to its length of the ion side, the LAMP spectrometer can be successfully used as a mass spectrometer. Using $k=\frac{q}{m}$, one can approximate the resolution of a spectrometer with a long drift tube by

$$
\frac{\Delta k}{k}=-2 \frac{\Delta t}{t} \approx-2 \frac{\sqrt{U \times k}}{S_{\text {tube }} t},
$$

where $t$ is the measured time-of-flight of the particle, $U$ is the acceleration potential at the interaction region, and $S_{\text {tube }}$ is the length of the drift tube. From this functional form alone, it is clear that the mass resolution of the ion side of the double sided LAMP spectrometer is about 4 times better than that of integrating ion time-of-flight spectrometer since the drift tube is about 4 times longer. In general, $\Delta t$ for a specific $\mathrm{q} / \mathrm{m}$ species depends not only on the acceleration potential, $U$, but also on the fragment kinetic energy. For most atomic ("cold") fragments, it is limited by the instrumental resolution which, for a typical integrating mode of measurement, is about 10-20 ns, corresponding to the pulse-width of the detector signal. Applying the aforementioned formula to the case of $\mathrm{Xe}$ ions measured with the integrating ion time-of-flight spectrometer, one obtains $\Delta k / k \approx 1.6 \%$, which means that out of the 4 strongest peaks, all but $\mathrm{Xe}_{131}^{10+}$ and $\mathrm{Xe}_{132}^{10+}(\sim 0.7 \%$ difference $)$ 
are resolved, as reflected by the spectrum in Fig. 4. The LAMP spectrometer with the same extraction voltage would thus be expected to resolve even those two isotopes all the way up to a point where different charge state groups start overlapping (which is at $\mathrm{Xe}^{20+}$ ).

Due to the relatively large number of spectrometer electrodes and numerous mesh options, the spectrometer can also be operated in a reaction microscope (ReMi) or COLTRIMS type flat-field arrangement without making any changes to the physical geometry. The trajectories in Fig. 7(b) depict one such configuration where almost perfectly flat and uniform fields throughout the whole spectrometer are achieved in spite of the conical geometry of the electrodes around the interaction region (typical voltage settings for this configuration is shown in Table III). The particle trajectories are parallel without any sign of focusing. This type of spectrometer setup is particularly useful for 3D momentum resolved ion and/or electron spectroscopy. Due to the absence of trajectory focusing, the TOF direction momentum resolution is typically better than in the VMI mode, while the position resolution is more dependent on the interaction region extent. The highest energy of the particles detected with $4 \pi$ efficiency is lower than that in the VMI arrangement. The energies used to generate the SIMION trajectories in Fig. 7(b), for example, were $45 \mathrm{eV} /$ unit-charge for ions and $100 \mathrm{eV}$ for electrons. Analogous reasoning as described above applies to this setup when it comes to the energy range extension either by using $10 \mathrm{kV}$ power supplies or by limiting the data collection to one side of the spectrometer at a time. Note that by applying appropriate voltages to the LAMP spectrometer electrodes, it is also possible to achieve a combination of VMI focusing on one side and flat fields on the other side of the spectrometer.

The earlier discussion of the VMI and REMI spectrometer setups implicitly assumed the presence of position sensitive detectors for either or both electron and ion sides. In the following, we will discuss the standard set of detectors that are used with the double-sided LAMP spectrometer. During the LAMP commissioning, the ion side of the spectrometer was equipped with a Roentdek $120 \mathrm{~mm}$ delay-line detector-DLD120. The square delay-line anode in combination with a $120 \mathrm{~mm} \mathrm{MCP}$ Z-stack of imaging quality is capable of measuring time-offlight and 2D coordinates for every ion hit, similarly to the HEX anode detector described in conjunction with the ion momentum spectrometer earlier (with the exception of the third, redundant layer). With properly chosen spectrometer geometry and extraction fields, this detector works very well for a simple ion TOF measurements even at rates of hundreds of ions per X-ray (or optical laser) shot. If the hit rate is reduced to several tens of ions per shot, the hit position of each of the ions can also be determined. However, in order to reach its full potential for coincident ion momentum detection, the hit rate should be below ten atomic or molecular ions per shot. Since the visualization of delay-line detector images is currently not yet implemented in the LCLS data-acquisition control and analysis software, a stand-alone data acquisition PC system based on the COBOLD PC software and TDC hardware from Roentdek, which can be run in parallel with the LCLS ACQIRIS data acquisition system, is used for online/offline delay-line image processing.
For the electron side of the spectrometer, a phosphor screen detector was used during the LAMP commissioning. Figure 9 presents an exemplary electron image that was measured during the commissioning. It shows the $2 \mathrm{D}$ electron momentum distribution of the low-energy part of the atomic neon photoelectron spectrum recorded at $900 \mathrm{eV}$ photon energy. The anisotropic outer ring corresponds to the $\mathrm{Ne}(1 \mathrm{~s})$ photoelectrons, while the peak at the center of the image corresponds to low-energy electrons stemming from double photoionization or double Auger decay. The highenergy valence and KVV-Auger electrons and not captured efficiently by the spectrometer. While an experimental test of the resolution of the electron VMI setup is yet to be performed, ideally with a narrow-bandwidth source such as a synchrotron or a seeded soft X-ray FEL, the field simulations and all the detector components were chosen to achieve a resolution of $\Delta \mathrm{E} / \mathrm{E}=1 / 100$ for the extracted electron energies. The MCPs of the phosphor detector are imaging quality Advanced Performance Long-Life ${ }^{\mathrm{TM}}$ MCPs from PHOTONIS with $75 \mathrm{~mm}$ active area diameter, $10 \mu \mathrm{m}$ pore size, and $12 \mu \mathrm{m}$ pitch, while the P47 phosphor screen produces blue light (peak emission wavelength of $430 \mathrm{~nm}$ ) with $\sim 100 \mathrm{~ns}$ decay time suitable for fast snapshot processing. The flange with the viewport and the phosphor screen detector is connected to the C1 12" port as an autonomous assembly and is not physically connected to the rest of the LAMP spectrometer. It can therefore be easily exchanged for a delay line detector in case an electron-ion coincidence at low count rate is to be performed.

While many experiments involving simultaneous detection of ions and electrons (and possibly also photons on the pnCCD detectors) can routinely utilize a covariance detection scheme, true ion-ion coincidence and, especially, ion-electron coincidence experiments require some extra measures to be taken to assure good signal-to-noise ratio (SNR). In an "open"

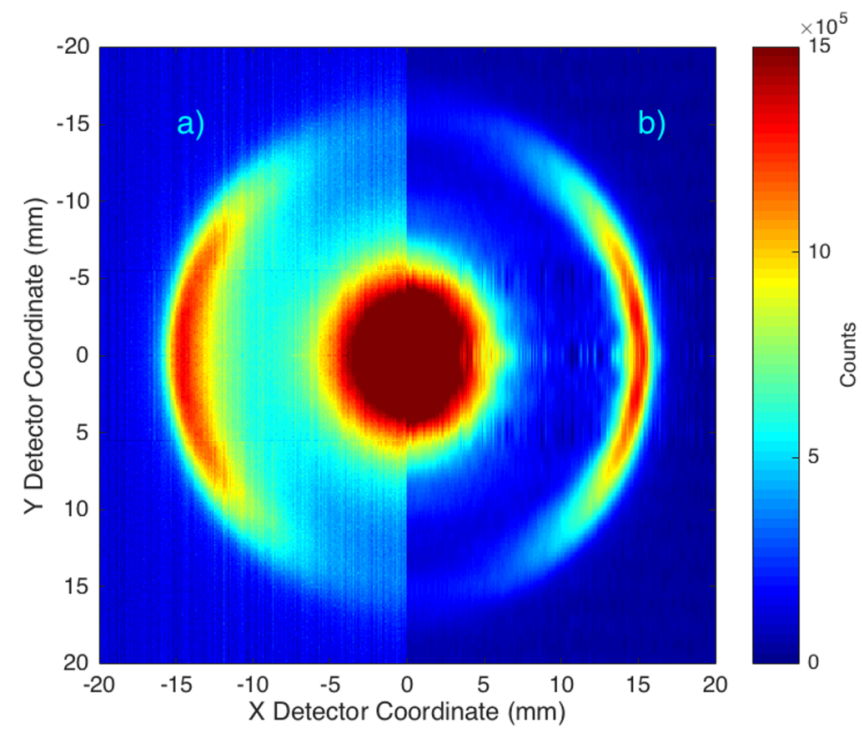

FIG. 9. 2D electron momentum distribution of the low-energy part of the neon photoelectron spectrum recorded at $900 \mathrm{eV}$ photon energy with the doublesided LAMP spectrometer in VMI mode equipped with a phosphor screen detector. (a) Raw detector image; (b) image after inverse-Abel-transform. The width of the 1 s photoelectron line is $<6 \mathrm{eV}$ and is consistent with the LCLS photon energy bandwidth and jitter $(\sim 0.7 \%$ out of $900 \mathrm{eV})$. 
spectrometer such as the ion-momentum-imaging spectrometer or double-sided LAMP spectrometer mentioned earlier, charged particles originating along the whole path of the $\mathrm{X}$-rays inside the spectrometer are detected. If the background gas consists of the same molecules as the sample jet, the SNR is given by $\rho_{\text {jet }} \cdot Z_{\text {jet }} / \rho_{\mathrm{bg}} \cdot Z_{\mathrm{bg}}$, where $\rho_{\text {jet }}, Z_{\text {jet }}, \rho_{\mathrm{bg}}, Z_{\mathrm{bg}}$ are the densities and the size of the interaction region along the $X$-ray direction for the jet and the background, respectively. With a jet density of $>10^{-9}$ particles per $\mathrm{cm}^{3}$, a background pressure of $<10^{-9} \mathrm{mbar}$, and $Z_{\text {jet }} / Z_{\mathrm{bg}} \sim 1 / 30$, the ratio of true coincidences coming from the jet to the ionization events coming from the background ends up being around 3/10. Note that such a low jet density is required to achieve a condition of a single target particle in the interaction region $(1.2 \mu \mathrm{m}$ $\times 1.2 \mu \mathrm{m} \times 1 \mathrm{~mm}$ ) for a given $\mathrm{X}$-ray shot since an intense LCLS pulse typically ionizes every molecule in the interaction region. If a better SNR is required, it can either be achieved by reaching a lower background pressure $\left(<10^{-9}\right.$ mbar $)$ or by considerably attenuating the $\mathrm{X}$-ray beam and increasing the jet density, thereby preserving the required coincidence condition of only ionizing a single target molecule per shot.

\section{CONCLUSION}

We have designed, built, and commissioned a new FEL end-station instrument named LAMP that provides a multifunctional, flexible, and modular system for user experiments in the AMO hutch at LCLS. The instrument is equipped with large-area X-ray photon detectors, and it is compatible with the existing AMO ion spectrometers. In addition, a new double-sided electron and ion imaging spectrometer was built in order to allow for electron and ion imaging simultaneous to X-ray photon detection. Exemplary results from the instrument commissioning demonstrate the functionality of the new instrument, which is available for user experiments. First user experiments have shown that the new instrument is well suited for mass-to-charge spectroscopy of heavy target molecules, clusters, droplets, and polymers, as well as for multi-particle coincident momentum spectroscopy performed simultaneously with highly efficient scattered and fluorescent light detection. This instrument is also planned to be used in the future LCLS-II facility, which is being designed and scheduled to be ready for operation in 2020 .

\section{ACKNOWLEDGMENTS}

This work was supported in part by a SISGR Grant No. DE-SC0002004 to N. Berrah from the U.S. Department of Energy Office of Science, Basic Energy Sciences, Division of Chemical Sciences, Geosciences, and Biosciences. Use of the Linac Coherent Light Source (LCLS), SLAC National Accelerator Laboratory, is supported by the U.S. Department of Energy, Office of Science, Office of Basic Energy Sciences under Contract No. DE-AC02-76SF00515.

We wish to thank the Max Planck Society and the CAMP team, in particular Joachim Ullrich, Sascha Epp, Robert Hartmann, and Lothar Strüder for providing complete drawings of the CAMP instrument and the CAMP spectrometers and for numerous helpful discussions during the design process of the LAMP instrument. We also thank Vladimir Petrovic and Philip Bucksbaum for allowing us to collect some of the spectrometer commissioning data during their LCLS experiment, and we thank the entire LCLS staff for their assistance during the design, construction, and commissioning of the LAMP instrument.

\section{APPENDIX: TYPICAL VOLTAGE SETTINGS FOR THE CHARGED-PARTICLE SPECTROMETERS}

TABLE I. Typical voltage settings used for the ion momentum imaging spectrometer in the ReMi configuration.

\begin{tabular}{lcc}
\hline \hline Electrode name & Flange label & Voltage (V) \\
\hline HEX signal & $\mathrm{n} / \mathrm{a}$ & 500 \\
HEX reference & $\mathrm{n} / \mathrm{a}$ & 450 \\
HEX holder & V0 & 100 \\
MCP Z-back & VA & Ground \\
MCP Z-front & 9 & -2500 \\
MCP holder & 8 & -2250 \\
DRIFT tube & L4 & Ground \\
Lens & L3 & 482 \\
Extractor & L2 & 1207 \\
Pusher & L1 & 2174 \\
\hline \hline
\end{tabular}

TABLE II. Typical voltage settings for the double-sided electron-ion spectrometer to produce a velocity map imaging (VMI) field arrangement.

\begin{tabular}{lcc}
\hline \hline Electrode name & Flange label & Voltage (V) \\
\hline El. tube & L0 & 2730 \\
El. focus lens & L1 & 1040 \\
El. conical 53 & L2 & 500 \\
El. conical 70 & L3 & -250 \\
Ion conical 70 & L5 & -875 \\
Ion conical 53 & L6 & -1500 \\
Ion focus lens \#1 & L7 & -1805 \\
Ion focus lens \#2 & L8 & -1915 \\
Ion focus lens \#3 & L9 & -3080 \\
Ion tube & D2 & -3680 \\
\hline \hline
\end{tabular}

TABLE III. Typical voltage settings for the double-sided electron-ion spectrometer to produce a reaction microscope (ReMi) field arrangement.

\begin{tabular}{lcc}
\hline \hline Electrode name & Flange label & Voltage (V) \\
\hline El. tube & L0 & 1810 \\
El. focus lens & L1 & 1015 \\
El. conical 53 & L2 & 344 \\
El. conical 70 & L3 & -426 \\
Ion conical 70 & L5 & -1023 \\
Ion conical 53 & L6 & -1693 \\
Ion focus lens \#1 & L7 & -2364 \\
Ion focus lens \#2 & L8 & -3109 \\
Ion focus lens \#3 & L9 & -3855 \\
Ion tube & D2 & -4600 \\
\hline \hline
\end{tabular}


${ }^{1}$ J. Feldhaus, J. Arthur, and J. Hastings, J. Phys. B: At., Mol. Opt. Phys. 38, S799 (2005).

${ }^{2}$ W. Ackermann, G. Asova, V. Ayvazyan, A. Azima, N. Baboi, J. Bähr, V. Balandin, B. Beutner, A. Brandt, A. Bolzmann et al., Nat. Photonics 1, 336 (2007).

${ }^{3}$ P. Emma, R. Akre, J. Arthur, R. Bionta, C. Bostedt, J. Bozek, A. Brachmann, P. Bucksbaum, R. Coffee, F.-J. Decker et al., Nat. Photonics 4, 641 (2010).

${ }^{4}$ E. Allaria, R. Appio, L. Badano, W. Barletta, S. Bassanese, S. Biedron, A. Borga, E. Busetto, D. Castronovo, P. Cinquegrana et al., Nat. Photonics 6, 699 (2012)

${ }^{5}$ T. Ishikawa, H. Aoyagi, T. Asaka, Y. Asano, N. Azumi, T. Bizen, H. Ego, K. Fukami, T. Fukui, Y. Furukawa et al., Nat. Photonics 6, 540 (2012).

${ }^{6}$ N. Berrah and P. H. Bucksbaum, Sci. Am. 310, 64 (2014).

${ }^{7}$ B. W. McNeil and N. R. Thompson, Nat. Photonics 4, 814 (2010).

${ }^{8}$ R. Neutze, R. Wouts, D. van der Spoel, E. Weckert, and J. Hajdu, Nature 406, 752 (2000).

${ }^{9}$ P. H. Bucksbaum, R. Coffee, and N. Berrah, Adv. At., Mol., Opt. Phys. 60, 239 (2011)

${ }^{10}$ C. Bostedt, J. Bozek, P. Bucksbaum, R. Coffee, J. Hastings, Z. Huang, R. Lee, S. Schorb, J. Corlett, P. Denes et al., J. Phys. B: At., Mol. Opt. Phys. 46, 164003 (2013).

${ }^{11}$ L. Fang, T. Osipov, B. Murphy, A. Rudenko, D. Rolles, V. Petrovic, C. Bostedt, J. Bozek, P. Bucksbaum, and N. Berrah, J. Phys. B: At., Mol. Opt. Phys. 47, 124006 (2014).

${ }^{12}$ A. Rudenko and D. Rolles, J. Electron Spectrosc. Relat. Phenom. 204, 228 (2015).

${ }^{13}$ P. H. Bucksbaum and N. Berrah, Phys. Today 68(7), 26 (2015).

${ }^{14}$ C. Bostedt, S. Boutet, D. M. Fritz, Z. Huang, H. J. Lee, H. T. Lemke, A. Robert, W. F. Schlotter, J. J. Turner, and G. J. Williams, Rev. Mod. Phys. 88, 015007 (2016).

${ }^{15}$ L. Young, E. Kanter, B. Krässig, Y. Li, A. March, S. Pratt, R. Santra, S. Southworth, N. Rohringer, L. DiMauro et al., Nature 466, 56 (2010).

${ }^{16}$ M. Hoener, L. Fang, O. Kornilov, O. Gessner, S. T. Pratt, M. Gühr, E. P. Kanter, C. Blaga, C. Bostedt, J. D. Bozek et al., Phys. Rev. Lett. 104, 253002 (2010).

${ }^{17}$ J. P. Cryan, J. M. Glownia, J. Andreasson, A. Belkacem, N. Berrah, C. I. Blaga, C. Bostedt, J. Bozek, C. Buth, L. F. DiMauro et al., Phys. Rev. Lett. 105, 083004 (2010).

${ }^{18}$ L. Fang, M. Hoener, O. Gessner, F. Tarantelli, S. T. Pratt, O. Kornilov, C. Buth, M. Gühr, E. P. Kanter, C. Bostedt et al., Phys. Rev. Lett. 105, 083005 (2010).

${ }^{19}$ N. Berrah, J. Bozek, J. Costello, S. Düsterer, L. Fang, J. Feldhaus, H. Fukuzawa, M. Hoener, Y. Jiang, P. Johnsson et al., J. Mod. Opt. 57, 1015 (2010).

${ }^{20}$ J. M. Glownia, J. Cryan, J. Andreasson, A. Belkacem, N. Berrah, C. Blaga, C. Bostedt, J. Bozek, L. DiMauro, L. Fang et al., Opt. Express 18, 17620 (2010).

${ }^{21}$ E. Kanter, B. Krässig, Y. Li, A. March, P. Ho, N. Rohringer, R. Santra, S. Southworth, L. DiMauro, G. Doumy et al., Phys. Rev. Lett. 107, 233001 (2011).

${ }^{22}$ G. Doumy, C. Roedig, S.-K. Son, C. I. Blaga, A. DiChiara, R. Santra, N. Berrah, C. Bostedt, J. Bozek, P. Bucksbaum et al., Phys. Rev. Lett. 106, 083002 (2011).

${ }^{23}$ N. Berrah, L. Fang, B. Murphy, T. Osipov, K. Ueda, E. Kukk, R. Feifel, P. Van Der Meulen, P. Salen, H. T. Schmidt et al., Proc. Natl. Acad. Sci. U. S. A. 108, 16912 (2011).

${ }^{24}$ L. Fang, T. Osipov, B. Murphy, F. Tarantelli, E. Kukk, J. Cryan, M. Glownia, P. Bucksbaum, R. Coffee, M. Chen et al., Phys. Rev. Lett. 109, 263001 (2012).

${ }^{25}$ V. S. Petrović, M. Siano, J. L. White, N. Berrah, C. Bostedt, J. D. Bozek, D. Broege, M. Chalfin, R. N. Coffee, J. Cryan et al., Phys. Rev. Lett. 108, 253006 (2012).

${ }^{26}$ N. Berrah, Phys. Chem. Chem. Phys. 19, 19536 (2017).

${ }^{27}$ P. Salén, P. van der Meulen, H. Schmidt, R. Thomas, M. Larsson, R. Feifel, M. N. Piancastelli, L. Fang, B. Murphy, T. Osipov et al., Phys. Rev. Lett. 108, 153003 (2012).

${ }^{28}$ T. Osipov, L. Fang, B. Murphy, M. Hoener, and N. Berrah, J. Phys.: Conf. Ser. 388, 012030 (2012).

${ }^{29}$ S. Vinko, O. Ciricosta, B. Cho, K. Engelhorn, H.-K. Chung, C. Brown, T. Burian, J. Chalupskỳ, R. Falcone, C. Graves et al., Nature 482, 59 (2012).

${ }^{30}$ S. Boutet, L. Lomb, G. J. Williams, T. R. Barends, A. Aquila, R. B. Doak, U. Weierstall, D. P. DePonte, J. Steinbrener, R. L. Shoeman et al., Science 337, 362 (2012).
${ }^{31}$ M. Dell'Angela, T. Anniyev, M. Beye, R. Coffee, A. Föhlisch, J. Gladh, T. Katayama, S. Kaya, O. Krupin, J. LaRue et al., Science 339, 1302 (2013).

${ }^{32}$ L. Frasinski, V. Zhaunerchyk, M. Mucke, R. J. Squibb, M. Siano, J. H. Eland, P. Linusson, P. Vd Meulen, P. Salén, R. Thomas et al., Phys. Rev. Lett. 111, 073002 (2013).

${ }^{33}$ J. Castagna, B. Murphy, J. Bozek, and N. Berrah, J. Phys.: Conf. Ser. 425, 152021 (2013).

${ }^{34}$ L. Redecke, K. Nass, D. P. DePonte, T. A. White, D. Rehders, A. Barty, F. Stellato, M. Liang, T. R. Barends, S. Boutet et al., Science 339, 227 (2013).

${ }^{35}$ B. Murphy, T. Osipov, Z. Jurek, L. Fang, S.-K. Son, M. Mucke, J. Eland, V. Zhaunerchyk, R. Feifel, L. Avaldi et al., Nat. Commun. 5, 4281 (2014).

${ }^{36}$ N. Berrah, L. Fang, T. Osipov, Z. Jurek, B. Murphy, and R. Santra, Faraday Discuss. 171, 471 (2014).

${ }^{37}$ N. Berrah, L. Fang, T. Osipov, B. Murphy, C. Bostedt, and J. Bozek, J. Electron Spectrosc. Relat. Phenom. 196, 34 (2014).

${ }^{38}$ B. McFarland, J. Farrell, S. Miyabe, F. Tarantelli, A. Aguilar, N. Berrah, C. Bostedt, J. Bozek, P. Bucksbaum, J. Castagna et al., Nat. Commun. 5, 4235 (2014).

${ }^{39}$ C. E. Liekhus-Schmaltz, I. Tenney, T. Osipov, A. Sanchez-Gonzalez, N. Berrah, R. Boll, C. Bomme, C. Bostedt, J. D. Bozek, S. Carron et al., Nat. Commun. 6, 8199 (2015).

${ }^{40}$ H. Öström, H. Öberg, H. Xin, J. LaRue, M. Beye, M. Dell'Angela, J. Gladh, M. Ng, J. A. Sellberg, S. Kaya et al., Science 347, 978 (2015).

${ }^{41}$ P. Wernet, K. Kunnus, I. Josefsson, I. Rajkovic, W. Quevedo, M. Beye, S. Schreck, S. Grübel, M. Scholz, D. Nordlund et al., Nature 520, 78 (2015).

${ }^{42}$ T. Kierspel, J. Wiese, T. Mullins, J. Robinson, A. Aquila, A. Barty, R. Bean, R. Boll, S. Boutet, P. Bucksbaum et al., J. Phys. B: At., Mol. Opt. Phys. 48 , 204002 (2015).

${ }^{43}$ N. Berrah, B. Murphy, H. Xiong, L. Fang, T. Osipov, E. Kukk, M. Guehr, R. Feifel, V. Petrovic, K. Ferguson et al., J. Mod. Opt. 63, 390 (2016).

${ }^{44}$ N. Berrah and L. Fang, J. Electron Spectrosc. Relat. Phenom. 204, 284 (2015).

${ }^{45}$ A. Picón, C. Lehmann, C. Bostedt, A. Rudenko, A. Marinelli, T. Osipov, D. Rolles, N. Berrah, C. Bomme, M. Bucher et al., Nat. Commun. 7, 11652 (2016).

${ }^{46}$ R. Boll, B. Erk, R. Coffee, S. Trippel, T. Kierspel, C. Bomme, J. D. Bozek, M. Burkett, S. Carron, K. R. Ferguson et al., Struct. Dyn. 3, 043207 (2016).

${ }^{47}$ C. Lehmann, A. Picón, C. Bostedt, A. Rudenko, A. Marinelli, D. Moonshiram, T. Osipov, D. Rolles, N. Berrah, C. Bomme et al., Phys. Rev. A 94, 013426 (2016).

${ }^{48}$ A. Rudenko, L. Inhester, K. Hanasaki, X. Li, S. Robatjazi, B. Erk, R. Boll, K. Toyota, Y. Hao, O. Vendrell et al., Nature 546, 129 (2017).

${ }^{49}$ C. Bostedt, H. N. Chapman, J. T. Costello, J. R. C. López-Urrutia, S. Düsterer, S. W. Epp, J. Feldhaus, A. Föhlisch, M. Meyer, T. Möller et al., Nucl. Instrum. Methods Phys. Res., Sect. A 601, 108 (2009).

${ }^{50}$ B. Nagler, U. Zastrau, R. R. Fäustlin, S. M. Vinko, T. Whitcher, A. Nelson, R. Sobierajski, J. Krzywinski, J. Chalupsky, E. Abreu et al., Nat. Phys. 5, 693 (2009).

${ }^{51}$ C. Bostedt, M. Adolph, E. Eremina, M. Hoener, D. Rupp, S. Schorb, H. Thomas, A. De Castro, and T. Möller, J. Phys. B: At., Mol. Opt. Phys. 43, 194011 (2010).

${ }^{52}$ C. Bostedt, E. Eremina, D. Rupp, M. Adolph, H. Thomas, M. Hoener, A. De Castro, J. Tiggesbäumker, K.-H. Meiwes-Broer, T. Laarmann et al., Phys. Rev. Lett. 108, 093401 (2012).

${ }^{53}$ H. Thomas, A. Helal, K. Hoffmann, N. Kandadai, J. Keto, J. Andreasson, B. Iwan, M. Seibert, N. Timneanu, J. Hajdu et al., Phys. Rev. Lett. 108, 133401 (2012).

${ }^{54}$ Y. Jiang, A. Senftleben, M. Kurka, A. Rudenko, L. Foucar, O. Herrwerth, M. F. Kling, M. Lezius, J. Tilborg, A. Belkacem et al., J. Phys. B: At., Mol. Opt. Phys. 46, 164027 (2013).

${ }^{55}$ K. Schnorr, A. Senftleben, M. Kurka, A. Rudenko, L. Foucar, G. Schmid, A. Broska, T. Pfeifer, K. Meyer, D. Anielski et al., Phys. Rev. Lett. 111, 093402 (2013).

${ }^{56}$ H. Fukuzawa, S.-K. Son, K. Motomura, S. Mondal, K. Nagaya, S. Wada, X.-J. Liu, R. Feifel, T. Tachibana, Y. Ito et al., Phys. Rev. Lett. 110, 173005 (2013).

${ }^{57}$ H. Yumoto, H. Mimura, T. Koyama, S. Matsuyama, K. Tono, T. Togashi, Y. Inubushi, T. Sato, T. Tanaka, T. Kimura et al., Nat. Photonics 7, 43 (2013).

${ }^{58}$ K. Motomura, E. Kukk, H. Fukuzawa, S.-i. Wada, K. Nagaya, S. Ohmura, S. Mondal, T. Tachibana, Y. Ito, R. Koga et al., J. Phys. Chem. Lett. 6, 2944 (2015).

${ }^{59}$ T. Tachibana, Z. Jurek, H. Fukuzawa, K. Motomura, K. Nagaya, S. Wada, P. Johnsson, M. Siano, S. Mondal, Y. Ito et al., Sci. Rep. 5, 10977 (2015). 
${ }^{60}$ H. N. Chapman, P. Fromme, A. Barty, T. A. White, R. A. Kirian, A. Aquila, M. S. Hunter, J. Schulz, D. P. DePonte, U. Weierstall et al., Nature 470, 73 (2011).

${ }^{61}$ M. M. Seibert, T. Ekeberg, F. R. Maia, M. Svenda, J. Andreasson, O. Jönsson, D. Odić, B. Iwan, A. Rocker, D. Westphal et al., Nature 470, 78 (2011).

${ }^{62}$ N. Loh, C. Y. Hampton, A. V. Martin, D. Starodub, R. G. Sierra, A. Barty, A. Aquila, J. Schulz, L. Lomb, J. Steinbrener et al., Nature 486, 513 (2012).

${ }^{63}$ A. Barty, C. Caleman, A. Aquila, N. Timneanu, L. Lomb, T. A. White, J. Andreasson, D. Arnlund, S. Bajt, T. R. Barends et al., Nat. Photonics 6, 35 (2012).

${ }^{64}$ B. Rudek, S.-K. Son, L. Foucar, S. W. Epp, B. Erk, R. Hartmann, M. Adolph, R. Andritschke, A. Aquila, N. Berrah et al., Nat. Photonics 6, 858 (2012).

${ }^{65}$ D. Starodub, A. Aquila, S. Bajt, M. Barthelmess, A. Barty, C. Bostedt, J. D. Bozek, N. Coppola, R. B. Doak, S. W. Epp et al., Nat. Commun. 3, 1276 (2012).

${ }^{66}$ R. Koopmann, K. Cupelli, L. Redecke, K. Nass, D. P. DePonte, T. A. White, F. Stellato, D. Rehders, M. Liang, J. Andreasson et al., Nat. Methods 9, 259 (2012).

${ }^{67}$ L. C. Johansson, D. Arnlund, T. A. White, G. Katona, D. P. DePonte, U. Weierstall, R. B. Doak, R. L. Shoeman, L. Lomb, E. Malmerberg et al., Nat. Methods 9, 263 (2012).

${ }^{68}$ T. Gorkhover, M. Adolph, D. Rupp, S. Schorb, S. W. Epp, B. Erk, L. Foucar, R. Hartmann, N. Kimmel, K.-U. Kühnel et al., Phys. Rev. Lett. 108, 245005 (2012).

${ }^{69}$ S. P. Hau-Riege, A. Graf, T. Döppner, R. A. London, J. Krzywinski, C. Fortmann, S. Glenzer, M. Frank, K. Sokolowski-Tinten, M. Messerschmidt et al., Phys. Rev. Lett. 108, 217402 (2012).

${ }^{70}$ A. V. Martin, N. Loh, C. Y. Hampton, R. G. Sierra, F. Wang, A. Aquila, S. Bajt, M. Barthelmess, C. Bostedt, J. D. Bozek et al., Opt. Express 20, 13501 (2012)

${ }^{71}$ S. Kassemeyer, J. Steinbrener, L. Lomb, E. Hartmann, A. Aquila, A. Barty, A. V. Martin, C. Y. Hampton, S. Bajt, M. Barthelmess et al., Opt. Express 20, 4149 (2012).

${ }^{72}$ A. Aquila, M. S. Hunter, R. B. Doak, R. A. Kirian, P. Fromme, T. A. White, J. Andreasson, D. Arnlund, S. Bajt, T. R. Barends et al., Opt. Express 20, 2706 (2012).

${ }^{73}$ B. Erk, D. Rolles, L. Foucar, B. Rudek, S. W. Epp, M. Cryle, C. Bostedt, S. Schorb, J. Bozek, A. Rouzee et al., Phys. Rev. Lett. 110, 053003 (2013).

${ }^{74}$ R. Boll, D. Anielski, C. Bostedt, J. D. Bozek, L. Christensen, R. Coffee, S. De, P. Decleva, S. W. Epp, B. Erk et al., Phys. Rev. A 88, 061402 (2013).

${ }^{75}$ B. Rudek, D. Rolles, S.-K. Son, L. Foucar, B. Erk, S. Epp, R. Boll, D. Anielski, C. Bostedt, S. Schorb et al., Phys. Rev. A 87, 023413 (2013).

${ }^{76}$ B. Erk, D. Rolles, L. Foucar, B. Rudek, S. Epp, M. Cryle, C. Bostedt, S. Schorb, J. Bozek, A. Rouzee et al., J. Phys. B: At., Mol. Opt. Phys. 46, 164031 (2013).

${ }^{77}$ E. Pedersoli, N. Loh, F. Capotondi, C. Hampton, R. Sierra, D. Starodub, C. Bostedt, J. Bozek, A. Nelson, M. Aslam et al., J. Phys. B: At., Mol. Opt. Phys. 46, 164033 (2013).

${ }^{78}$ B. Erk, R. Boll, S. Trippel, D. Anielski, L. Foucar, B. Rudek, S. W. Epp, R. Coffee, S. Carron, S. Schorb et al., Science 345, 288 (2014).

${ }^{79}$ L. F. Gomez, K. R. Ferguson, J. P. Cryan, C. Bacellar, R. M. P. Tanyag, C. Jones, S. Schorb, D. Anielski, A. Belkacem, C. Bernando et al., Science 345, 906 (2014).
${ }^{80}$ M. F. Hantke, D. Hasse, F. R. Maia, T. Ekeberg, K. John, M. Svenda, N. D. Loh, A. V. Martin, N. Timneanu, D. S. Larsson et al., Nat. Photonics 8, 943 (2014).

${ }^{81}$ J. Küpper, S. Stern, L. Holmegaard, F. Filsinger, A. Rouzée, A. Rudenko, P. Johnsson, A. V. Martin, M. Adolph, A. Aquila et al., Phys. Rev. Lett. 112 083002 (2014).

${ }^{82}$ D. Rolles, R. Boll, M. Adolph, A. Aquila, C. Bostedt, J. Bozek, H. Chapman, R. Coffee, N. Coppola, P. Decleva et al., J. Phys. B: At., Mol. Opt. Phys. 47, 124035 (2014).

${ }^{83}$ R. M. P. Tanyag, C. Bernando, C. F. Jones, C. Bacellar, K. R. Ferguson, D. Anielski, R. Boll, S. Carron, J. P. Cryan, L. Englert, S. W. Epp, B. Erk, L. Foucar, L. F. Gomez, R. Hartmann, D. M. Neumark, D. Rolles, B. Rudek, A. Rudenko, K. R. Siefermann, J. Ullrich, F. Weise, C. Bostedt, O. Gessner, and A. F. Vilesov, Struct. Dyn. 2, 051102 (2015).

${ }^{84}$ T. Ekeberg, M. Svenda, C. Abergel, F. R. Maia, V. Seltzer, J.-M. Claverie, M. Hantke, O. Jönsson, C. Nettelblad, G. Van Der Schot et al., Phys. Rev. Lett. 114, 098102 (2015).

${ }^{85}$ G. Van Der Schot, M. Svenda, F. R. Maia, M. Hantke, D. P. DePonte, M. M. Seibert, A. Aquila, J. Schulz, R. Kirian, M. Liang et al., Nat. Commun. 6, ncomms6704 (2015).

${ }^{86}$ T. Gorkhover, S. Schorb, R. Coffee, M. Adolph, L. Foucar, D. Rupp, A. Aquila, J. D. Bozek, S. W. Epp, B. Erk et al., Nat. Photonics 10, 93 (2016).

${ }^{87}$ C. F. Jones, C. Bernando, R. M. P. Tanyag, C. Bacellar, K. R. Ferguson, L. F. Gomez, D. Anielski, A. Belkacem, R. Boll, J. Bozek et al., Phys. Rev. B 93 180510 (2016).

${ }^{88}$ S. Schorb, D. Rupp, M. L. Swiggers, R. N. Coffee, M. Messerschmidt, G. Williams, J. D. Bozek, S.-I. Wada, O. Kornilov, T. Möller et al., Phys. Rev. Lett. 108, 233401 (2012).

${ }^{89}$ R. Obaid, C. Buth, G. L. Dakovski, R. Beerwerth, M. Holmes, J. Aldrich, M.-F. Lin, M. Minitti, T. Osipov, W. Schlotter et al., J. Phys. B: At., Mol. Opt. Phys. 51, 034003 (2018).

${ }^{90}$ L. Strüder, S. Epp, D. Rolles, R. Hartmann, P. Holl, G. Lutz, H. Soltau, R. Eckart, C. Reich, K. Heinzinger et al., Nucl. Instrum. Methods Phys. Res., Sect. A 614, 483 (2010).

${ }^{91}$ E. Gamboa, B. Bachmann, D. Kraus, M. MacDonald, M. Bucher, S. Carron, R. Coffee, R. Drake, J. Emig, K. Ferguson, S. Glenzer, T. Gorkhover, S. Hau-Riege, J. Krzywinski, A. Levitan, K.-H. Meiwes-Broer, T. Osipov, T. Pardini, C. Peltz, S. Skruszewicz, C. Bostedt, T. Fennel, and T. Döppner, J. Instrum. 11, P08015 (2016).

${ }^{92}$ A. Sanchez-Gonzalez, T. Barillot, R. Squibb, P. Kolorenč, M. Agaker, V. Averbukh, M. Bearpark, C. Bostedt, J. Bozek, S. Bruce et al., J. Phys. B At., Mol. Opt. Phys. 48, 234004 (2015).

${ }^{93}$ K. R. Ferguson, M. Bucher, J. D. Bozek, S. Carron, J.-C. Castagna, R. Coffee, G. I. Curiel, M. Holmes, J. Krzywinski, M. Messerschmidt et al., J. Synchrotron Radiat. 22, 492 (2015).

${ }^{94}$ J. D. Bozek, Eur. Phys. J. Spec. Top. 169, 129 (2009).

${ }^{95}$ K. R. Ferguson, M. Bucher, T. Gorkhover, S. Boutet, H. Fukuzawa, J. E. Koglin, Y. Kumagai, A. Lutman, A. Marinelli, M. Messerschmidt et al., Sci. Adv. 2, e1500837 (2016).

${ }^{96}$ R. Dörner, V. Mergel, O. Jagutzki, L. Spielberger, J. Ullrich, R. Moshammer, and H. Schmidt-Böcking, Phys. Rep. 330, 95 (2000).

${ }^{97}$ J. Ullrich, R. Moshammer, A. Dorn, R. Dörner, L. P. H. Schmidt, and H. Schmidt-Böcking, Rep. Prog. Phys. 66, 1463 (2003).

${ }^{98}$ A. T. Eppink and D. H. Parker, Rev. Sci. Instrum. 68, 3477 (1997). 